$33 / \gamma^{2} / 8^{\circ}$ $1^{\prime}$
LA-8404-MS

(ISPO-97)

Informal Report

\title{
Channel Coincidence Counter: Version 1
}

TO IAEA SAFEGUARDS

인

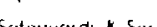

$\stackrel{7}{0}$

$\stackrel{\bar{D}}{5}$

DISTREGUTION OF THIS DOCUNENT IS UNLIMITED 
LA-8404-MS

(ISPO-97)

Informal Report

UC.15

Issued: June 1980

\title{
Channel Coincidence Counter: Version 1
}

\author{
Merlyn S. Krick \\ Howard O. Menlove
}

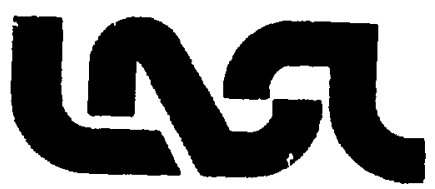

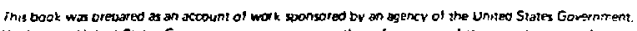

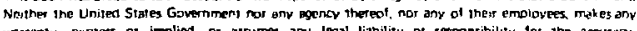

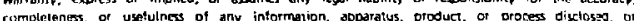

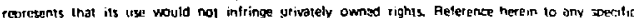

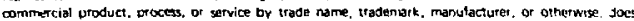
not neceswrily constitute or imply its endorement, recommensation, or tavoring by the Units Stales Government of any agchey thereot. The view and ppinions of authors expressed herent do not

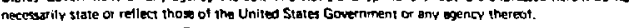


CHANNEL COINCIDENCE COUNTER: VERSION 1

by

Merlyn S. Krick and Howard O. Menlove

\begin{abstract}
A thermal neutron coincidence counter has been designed for the assay of fast critical assembly fuel drawers and plutonium-bearing fuel rods. The principal feature of the detector is a $7-\mathrm{cm}$ by $7 \mathrm{~cm}$ by $97 \mathrm{~cm}$ derector channel, which provides a uniform neutron detection efficiency of 168 along the central $40 \mathrm{~cm}$ of the channel. The electronics system is identical to that used for the High-Level Neutron Coincidence Counter.
\end{abstract}

\title{
I. INTRODUCTION
}

A custom neutron coincidence counter has been designed to improve the assay of fast critical assembly (FCA) fuel drawers and plutonium-bearing fuel rods. FCA drawers have been assayed with the High-Level Neutron Coincidence Counter (HLNCC), as shown in Fig. 1 and discussed previously. ${ }^{1,2}$ A two-position measurement is reguired with the HLNCC to provide uniform assay weight to the plutonium regardless of its axial position in the drawer. Figure 2 shows how the two-position sum provides a rather uniform response over a $40-\mathrm{cm}$ span, which is typical of the length of plutonium loading in an FCA drawer. There are four disadvantages to the measurement technique: 


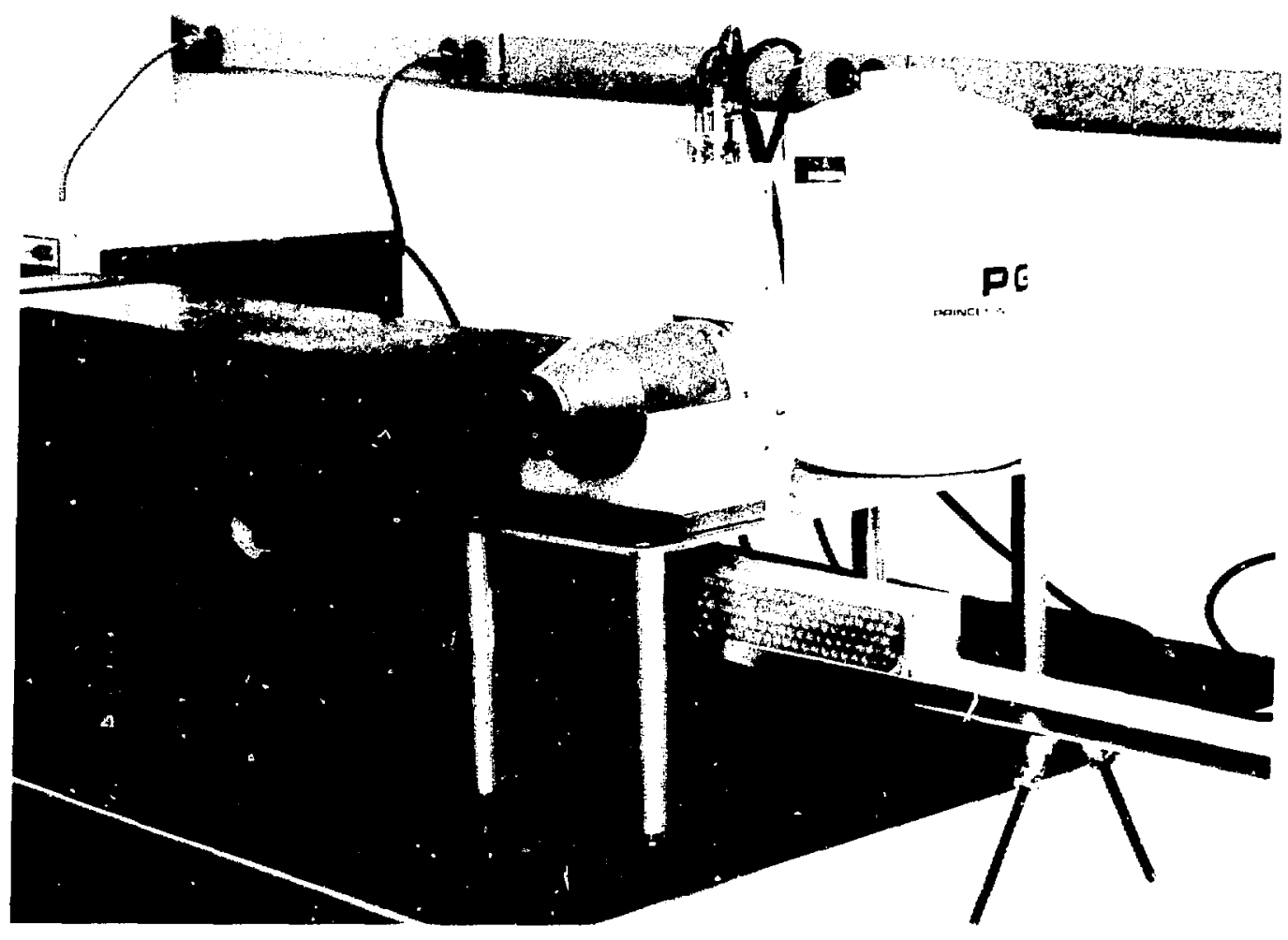

Fig. 1 .

HLNCC with mockup FCA fuel drawer and germanium detector.

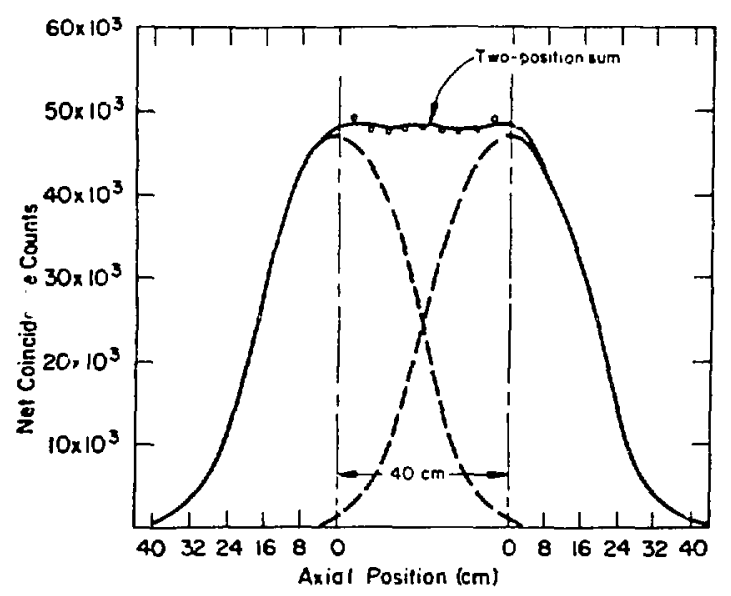

Fig. 2 .

Axial coincidence efficiency for the two-position count to obtain a uniform sum over an extended region $(40 \mathrm{~cm})$ (from Ref. 3). 
(1) the HLNCC must be reconfigured to perform the measurement,

(2) the open counting geometry reduces the HLNCC coincidence counting efficiency,

(3) the two-position measurement requires more time and is an inconvenience, and

(4) a slight positioning error can produce a $1-28$ assay error.

In consideration of these problems, a custom detector was designed for the assay of FCA drawers with a single, high-efficiency measurement. The coincidence rate for a fuel drawer in the channel detector is approximately three times higher than for the HLNCC, so an assay can be performed in about one-third the time for the same statistical precision. The channel detector is also more useful than the HLNCC for the assay of plutonium-bearing fuel rods.

II . THE DETECTOR

\section{A. Detector Body}

The detector is typical of thermal neutron coincidence counters in that it consists of ${ }^{3} \mathrm{He}$ proportional counters embedded in a cadmium-lined polyethylene assembly. An isometric view of the detector is shown in Fig. 3; a photograph of the complete detection system is shown in Fig. 4.

The principal feature of the detector is the $7 \mathrm{~cm}$ by $7 \mathrm{~cm}$ channel, which runs the full length $(97 \mathrm{~cm})$ of the detector. This channel is large enough to hold FCA fuel drawers and certain fuel rod trays, but is small enough to permit high and reasonably uniform coincidence-counting efficiency.

The cross-sectional dimensions of the detector (approximately $28 \mathrm{~cm}$ by $28 \mathrm{~cm}$ ) were determined largely by the desire for high efficiency and the easily available slabs of $7.6 \mathrm{~cm}(3$ in.) and $10.2 \mathrm{~cm}$ (4 in.) thick polyethylene. The detector, which weighs about $75 \mathrm{~kg}$, was not designed to be a portable instrument. 


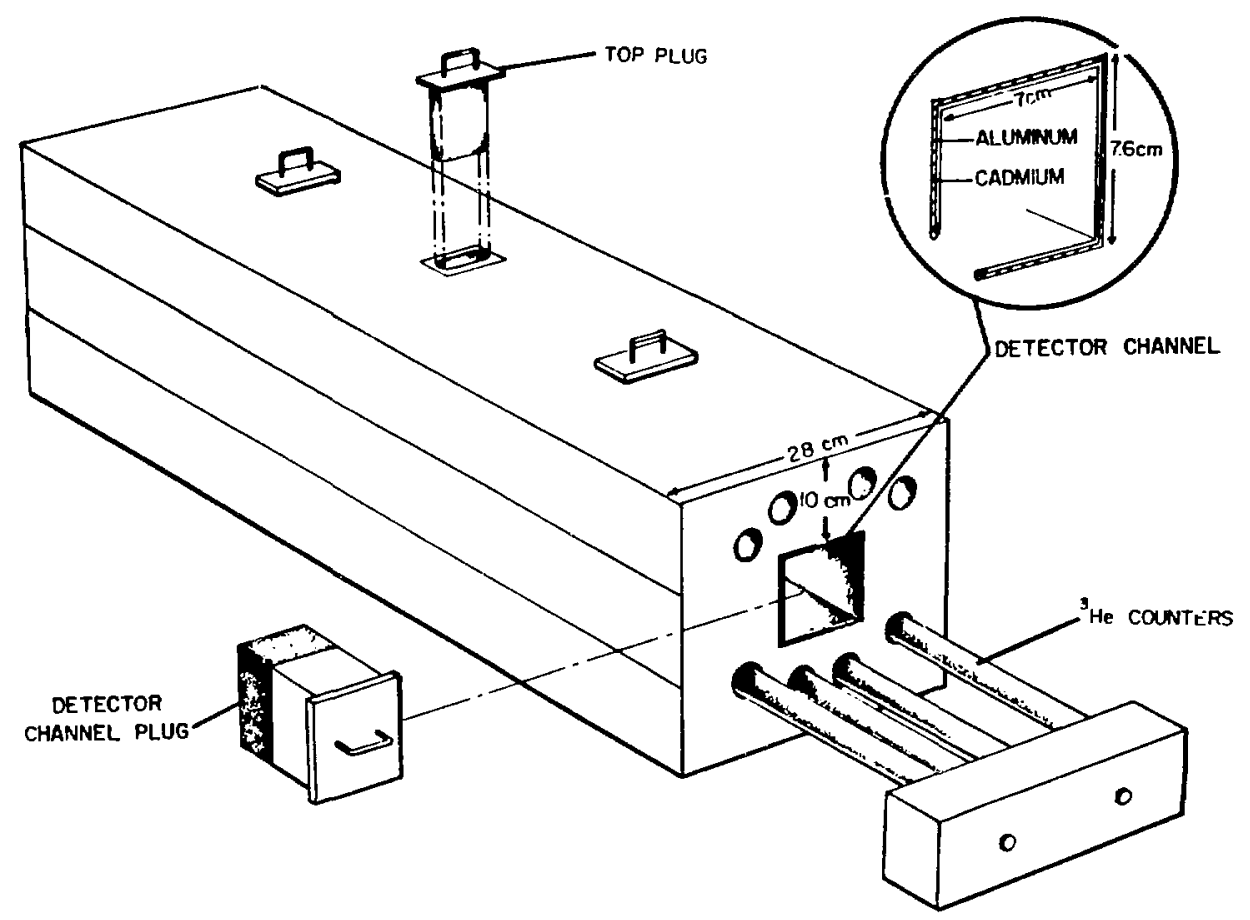

CHANNEL COINCIDENCE COUNTER

Fig. 3 .

Isometric view of channel detector.

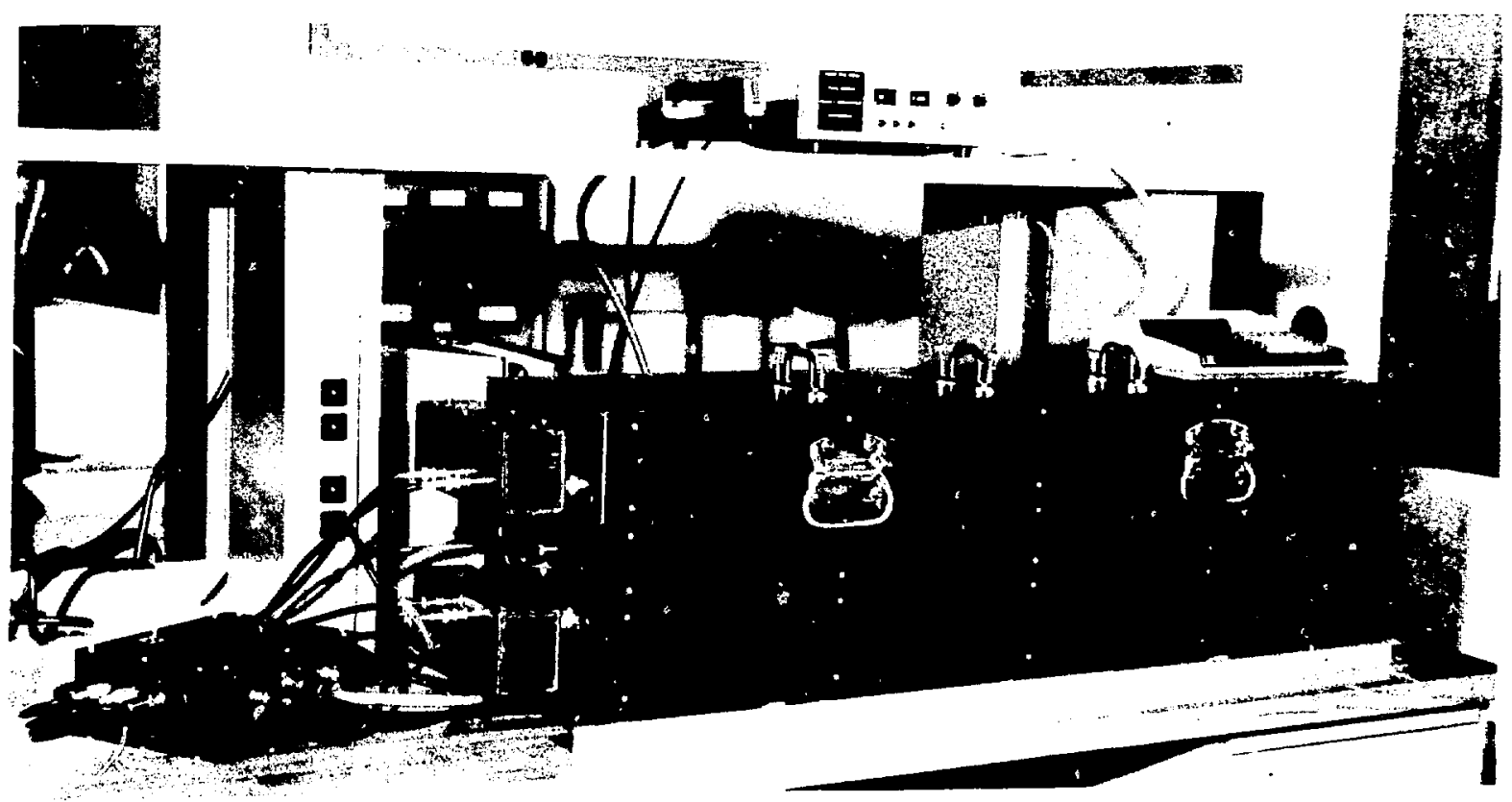

Fig. 4 .

Channel detector with electronics. 


$$
\geqslant
$$




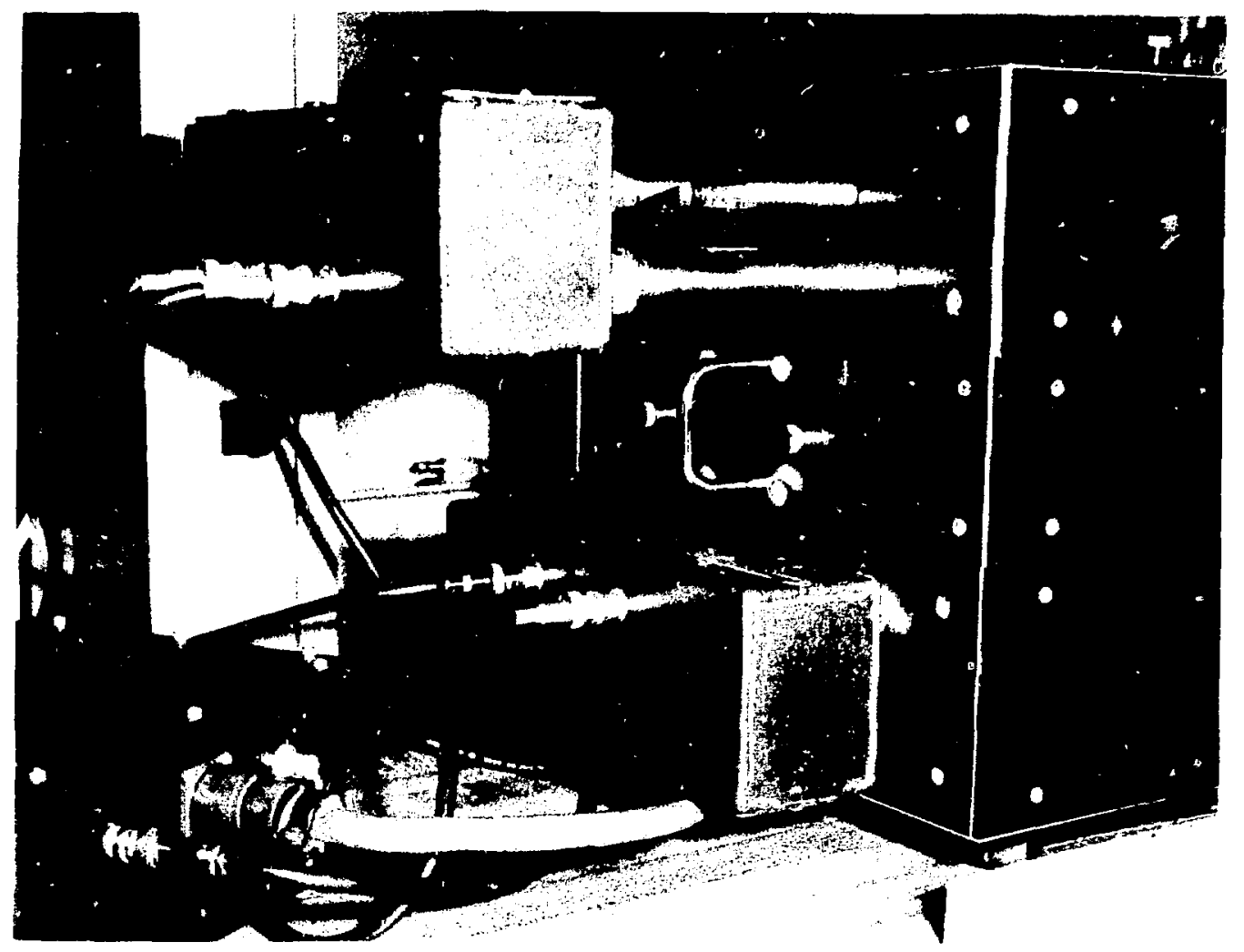

Fig. 6.

End view of channel detector showing end plug and $\mathrm{HV}$ junction boxes. The upper junction box was puller back to expose the ${ }^{3} \mathrm{He}$ tubes for the photograph.

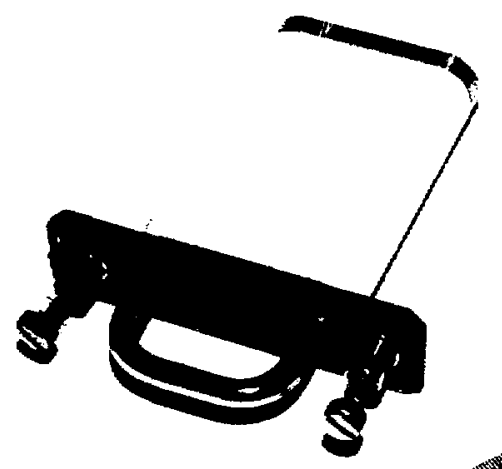

Fig. 7 .

Top plug. 


\section{B. Detector Tubes}

The neutron detectors are 4 atm ${ }^{3}$ He proportional counters with a $\mathrm{CO}_{2}$ additive gas, which provides improved gamma-ray insensitivity relative to an argon additive. Spurious neutron pulses should not be generated by the tubes in gamma-ray fields below $1 \mathrm{R} / \mathrm{h}$.

The tubes in the top and bottom slabs are not placed symmetrically; the two top center tubes were separated as needed to provide space for the gamma-ray slots. Eight tubes $12.5 \mathrm{~cm}$ diam by $91 \mathrm{~cm}$ active length) were used in the system, because eight provided adequate efficiency and because eight was the number available at the time of construction.

\section{Electronics}

The electronics packages used to operate the channel detector are identical to those used for the HLNCC. ${ }^{2}$ The eight tubes are connected as four pairs in two junction boxes (Fig. 6). Thus, only four of the six preamplifiers are connected, as shown in Fig. 8. The instrument was originally calibrated with a detector high voltage of $1500 \mathrm{~V}$ and a discrimination level of $1.25 \mathrm{~V}$.

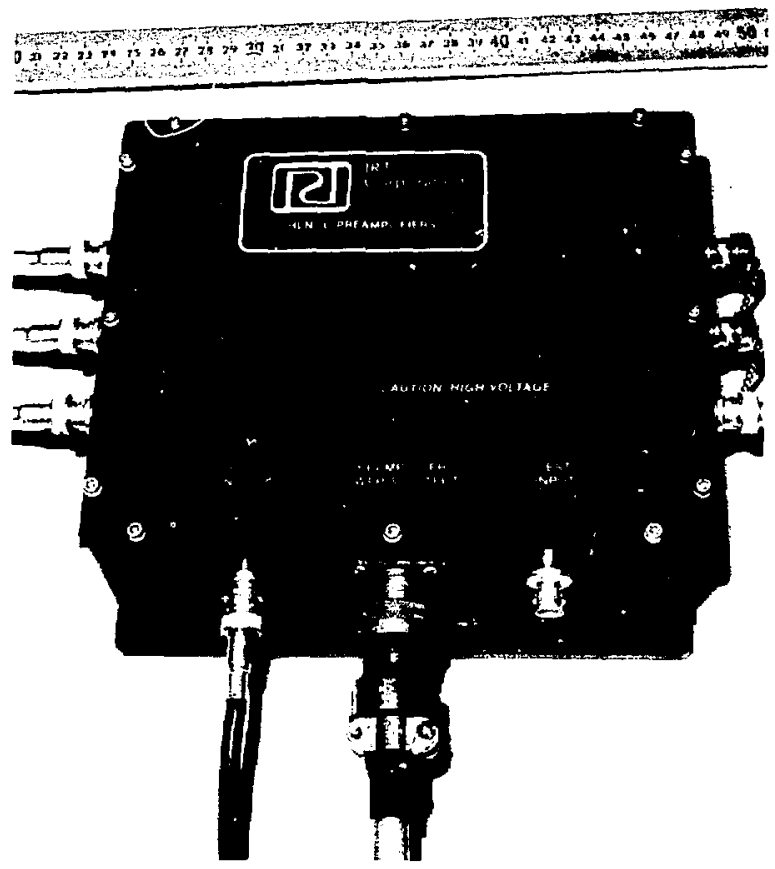

Fig. 8 .

Preamplifier box with cable connections and procective caps. 


\section{Calibration Source}

A 252 Cf spontaneous-fission source is included with the instrument for calibration measurements. The source had an original strength of approximately $4 \times 10^{4}$ neutrons/s and is physically identical to the HLNCi calibration sources. Figure 9 shows the source attached to its brass support. Figure 10 shows the source and brass support screwed as far as possible into the center top plug, which is the configuration used for calibration measurements; when the plug is inserted into the detector, the ${ }^{252} \mathrm{Cf}$ is centered in the channel. The source may be stored in the center top plug or in an HLNCC end plug.

\section{E. Fuel Tray}

A fuel tray, desiyned for use with the channel detector and the HLNCC, is supplied with the system (Figs, 11 and 12). The use of the tray is described later.
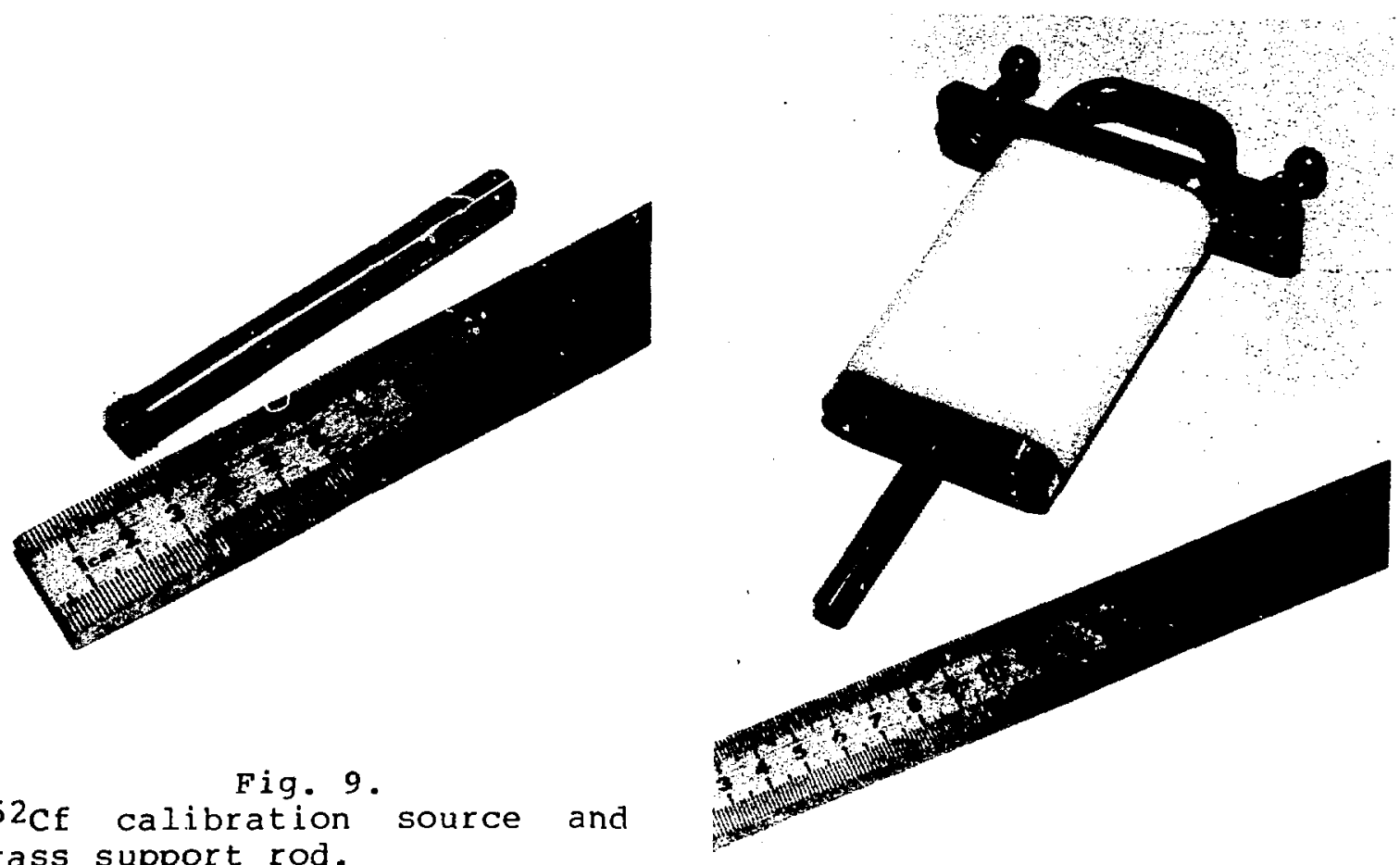

252 cf calibration source and brass support rod.

Fig. 10 .

Top plug with $252 \mathrm{Cf}$ fully inserted. 


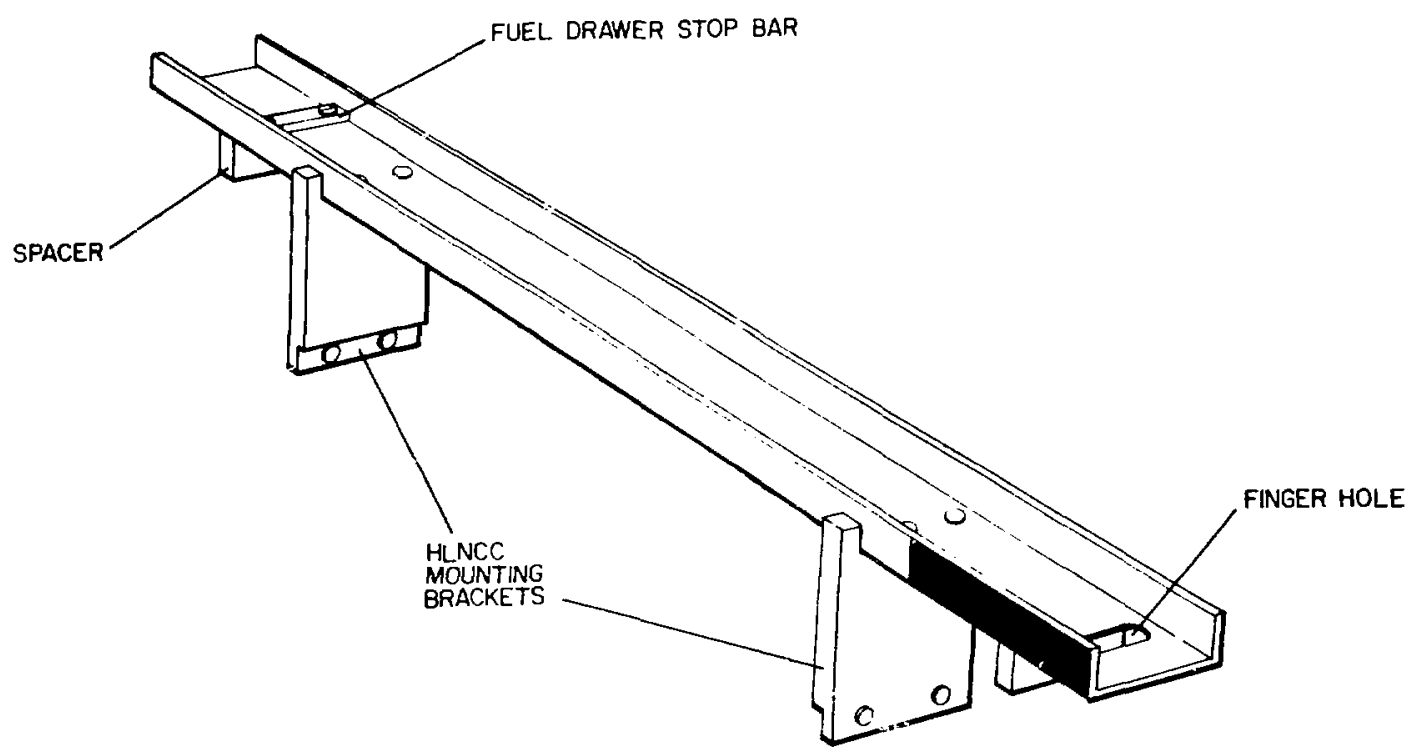

Fig. 11 .

Isometric view of fuel tray.

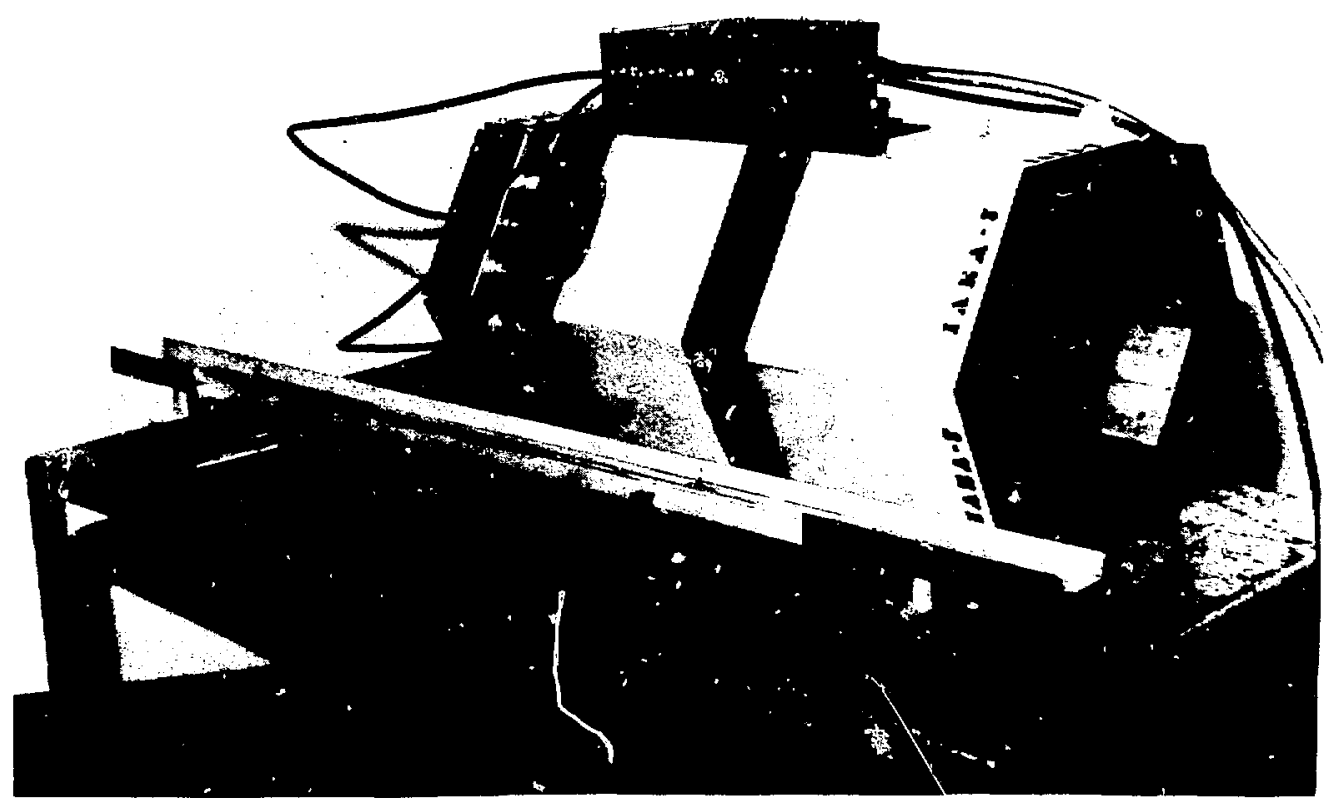

Fig. 12 .

Fuel tray shown in front of HLNCC. 
III. OPERATINI CHARACTERISTICS

A. Efficiency

A small $252 \mathrm{Cf}$ source with known neutron intensity was measured in the channel detector in the normal calibration position, i.e., inserted with the brass holder in the center top plug (Fig. 10). The absolute neutron detection efficiency $\varepsilon$ was determined to be

$$
\varepsilon=15.68 \text {. }
$$

\section{B. Detector Die-Away Time}

The coincidence rate was measured for gate widths from 8 to $128 \mathrm{\mu s}$. An analysis of these data gave a detector die-anay time of 73 is. Either 64 or 128 is gate widths are slitable for use with the channel detector. The original calibrations were performed with a 64 us gate.

\section{Dzadtime}

The coincidence deadime was calculated from a pair of measurements with a ${ }^{252} \mathrm{Cf}$ and a $24 \mathrm{I}_{\mathrm{Am}-\mathrm{Li}}$ source, with the result that the coincidence deadtime is approximately 3.3 is. The coincidence deadime correction formula is

$$
\dot{R}_{c}=\dot{R} \exp \left(\delta_{c} \dot{T}\right),
$$

where

$$
\begin{aligned}
& \dot{\mathrm{R}}_{\mathrm{C}}=\text { corrected coincidence rate, } \\
& \dot{\mathrm{R}}=\text { measured coincidence rate, } \\
& \dot{\delta}_{\mathrm{c}}=\text { coincidence deadtime }=3.3 \mu \mathrm{s}, \text { and } \\
& \dot{\mathrm{T}}=\text { measured totals rate }\left(\mathrm{s}^{-1}\right) .
\end{aligned}
$$

\section{Longitudinal Response}

A small ${ }^{252}$ ce source was measured along the centerline of the detector chanrel with end and top plugs in place. The normalized coincidence rate is plotted vs position in Fig. 13. The 
rate is constant within $2 \%$ over the central $40 \mathrm{~cm}$ of the channel and is constant within 58 over the central $50 \mathrm{~cm}$ of the channel. The result is only slightly affected by the presence or absence of the end plug.

\section{E. Vertical and Horizontal Response}

Vertical and horizontal cross-section coincidence response curves at the longitudinal center of the channel are plotted in Figs. 14 and 15, respectively. The vertical response is asymmetric because the top center ${ }^{3}$ He tubes are separated more than the bottom center ones to accommodate the gamma-ray slots. The horizontal response varies $+0 /-5 \%$ from its central value; the vertical response varies $+9 /-38$ from its central value.

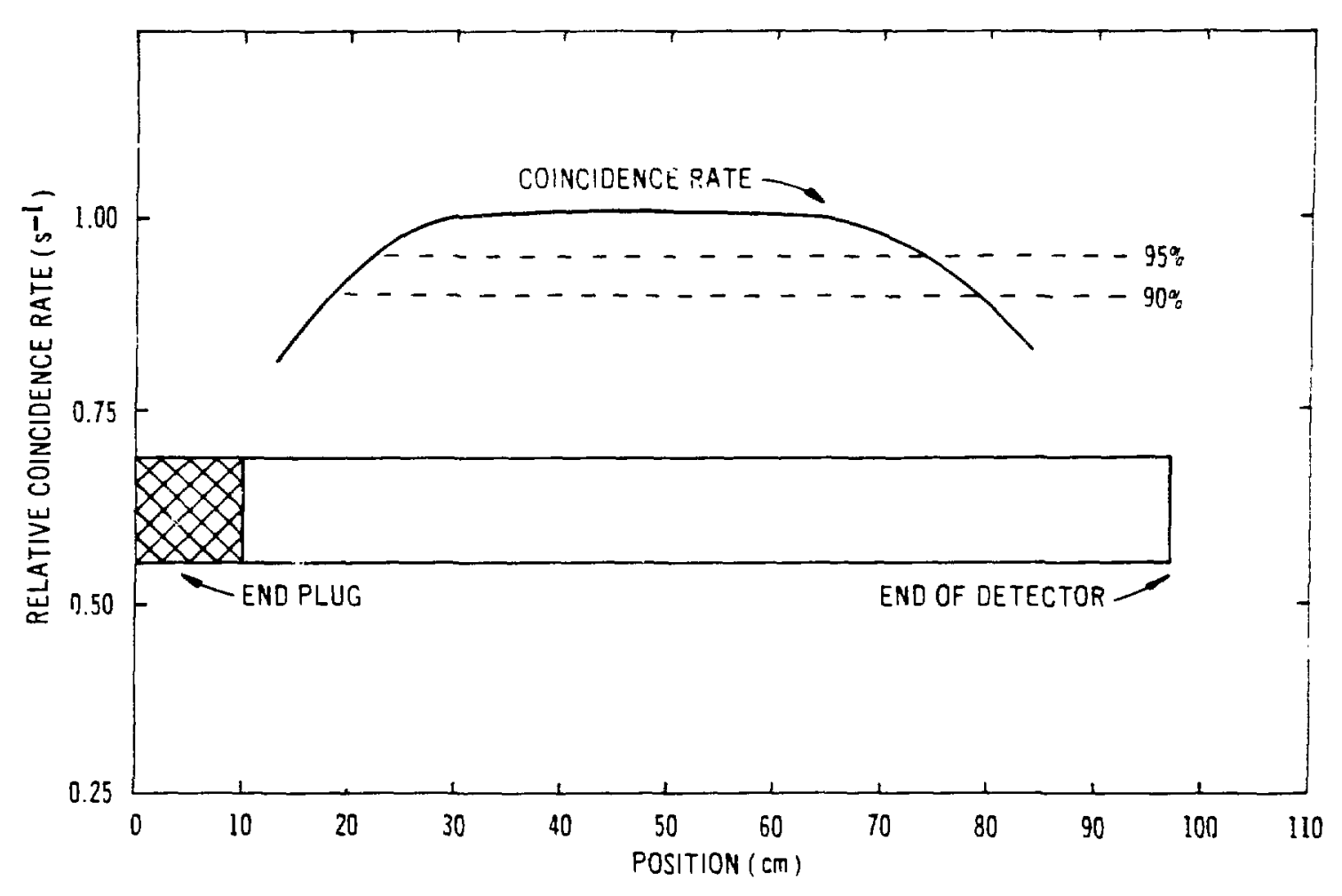

Fig. 13.

Longitudinal coincidence response of channel detector. 


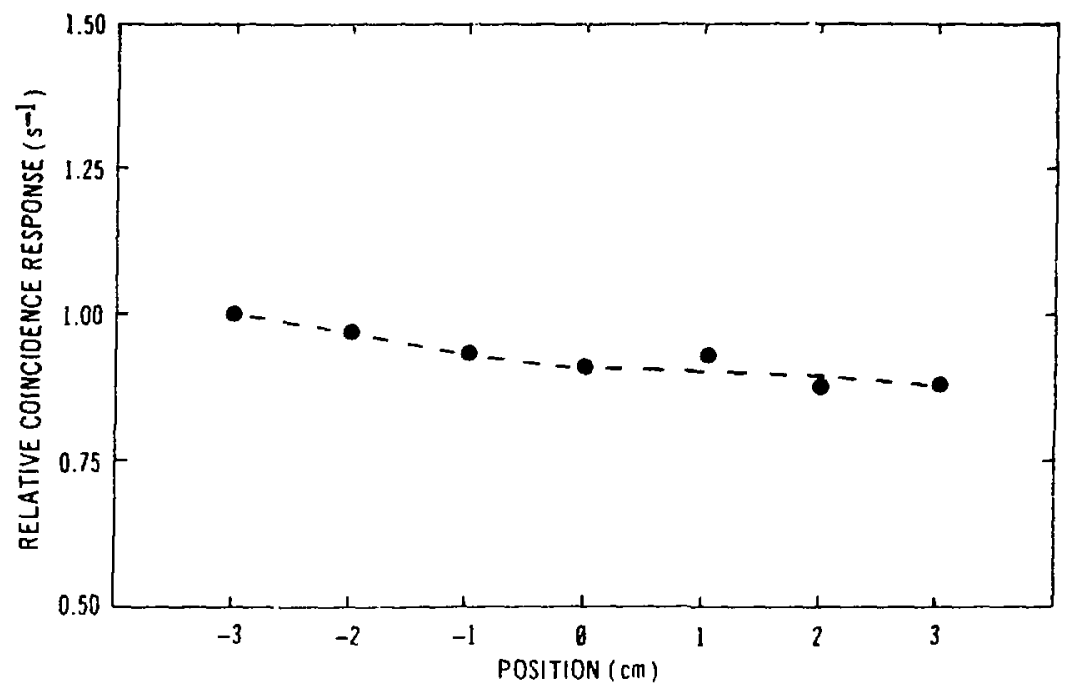

Fig. 14.

Coincidence response along vertical centerline of detector channel cross section at longitudinal center.

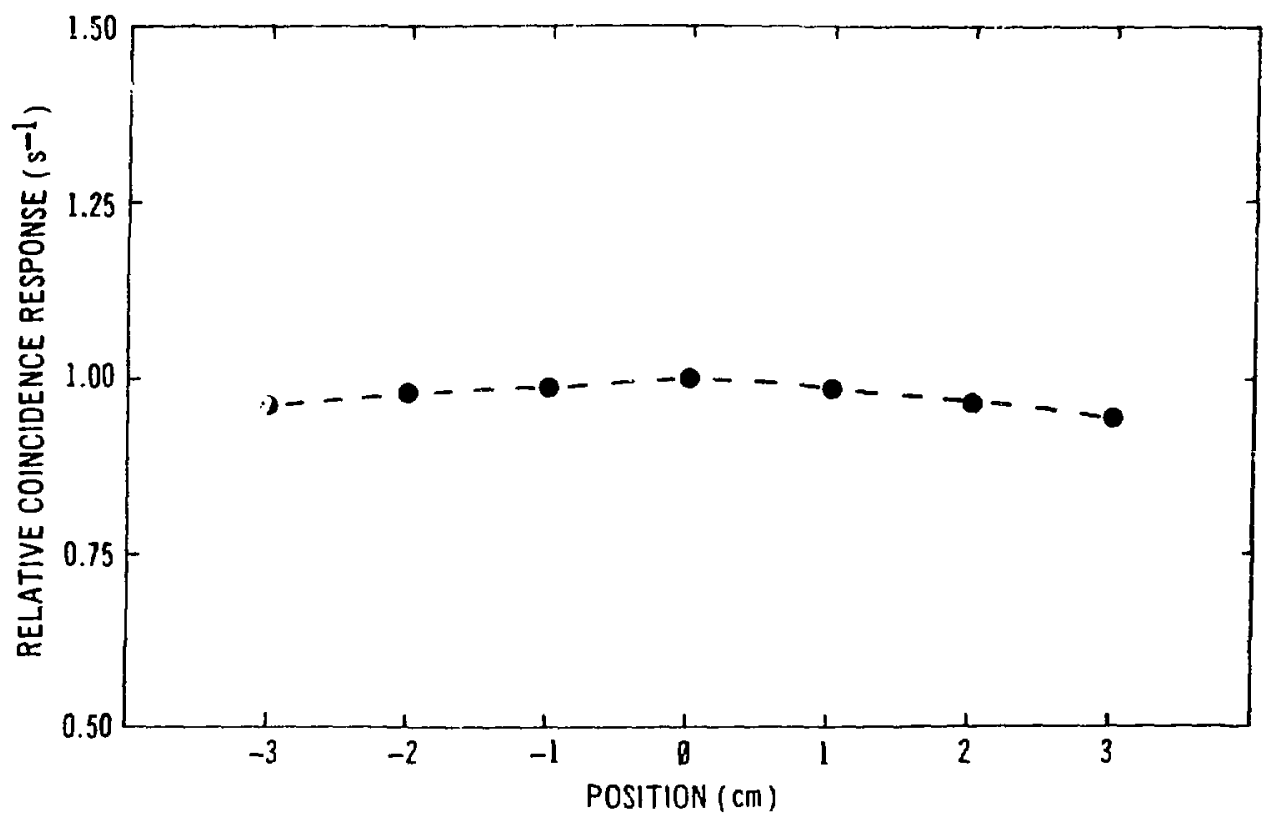

Fig. 15.

Coincidence response along horizontai centerline of detector channel cross section at longitudinal center. 
IV. OPERATING PROCEDURES

A. Checkout

The general checkout procedures are the same as for the HLNCC, except as follows:

(1) Connect four (rather than six) HV cables from the detectors to the preamp box; place protective caps on the two spare connectors (Fig. 8 ).

(2) Set the discrimination level to $1.25 \mathrm{~V}$ (2.50 on the dial).

(3) Set the gate length switch to $64 \mu \mathrm{s}$.

(4) The totals-to-reals ratio $(\dot{T} / \dot{R})$ for the ${ }^{252} \mathrm{Cf}$ calibration source should be approxinately 7.7 for the channel detector rather than 10.9 or 10.1 for the HLNCC.

B. Assay of FCA Fuel Drawers

The four lower brackets are removed from the fuel tray so that the bottom of the tray can glide on the bottom of the detector channel (Fig. 16).* The bar in the tray is used as a stop for the FCA drawers, as shown in Fig. 17.

The channel detector is operated with the end plug inserted and tightly fastened. The top plugs should be inserted unless a gamma-ray port is needed. (The ${ }^{252} \mathrm{Cf}$ source must be removed from the center plug.) The FCA drawer is placed on the tray against the stop as shown in Fig. 17; the depleted uranium block is at the end away from the stop. The tray is inserted into the channel until it is stopped by the end plug; this automatically positions an FCA drawer with a $40-\mathrm{cm}$ long plutonium fuel section in the flat-response region of the channel. Figure 16 shows the tray partially inserted with a mockup FCA drawer; Fig. 18 shows the same with the tray fully inserted.

\footnotetext{
"The bracket closest to the fingur hole can be retained, if desired.
} 


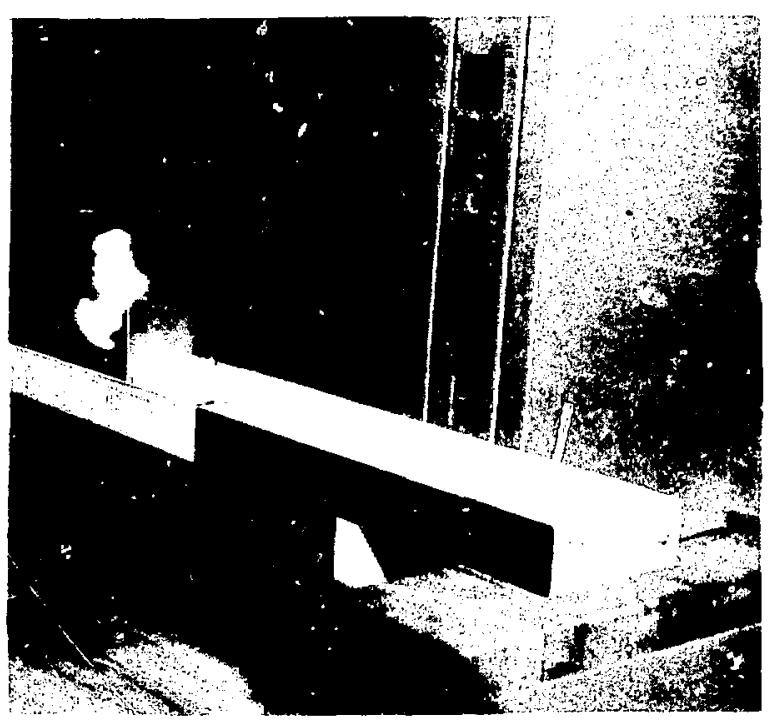

Fig. 16.

Fuel tray partially inserted in detector channel with mockup FCA fuel drawer.

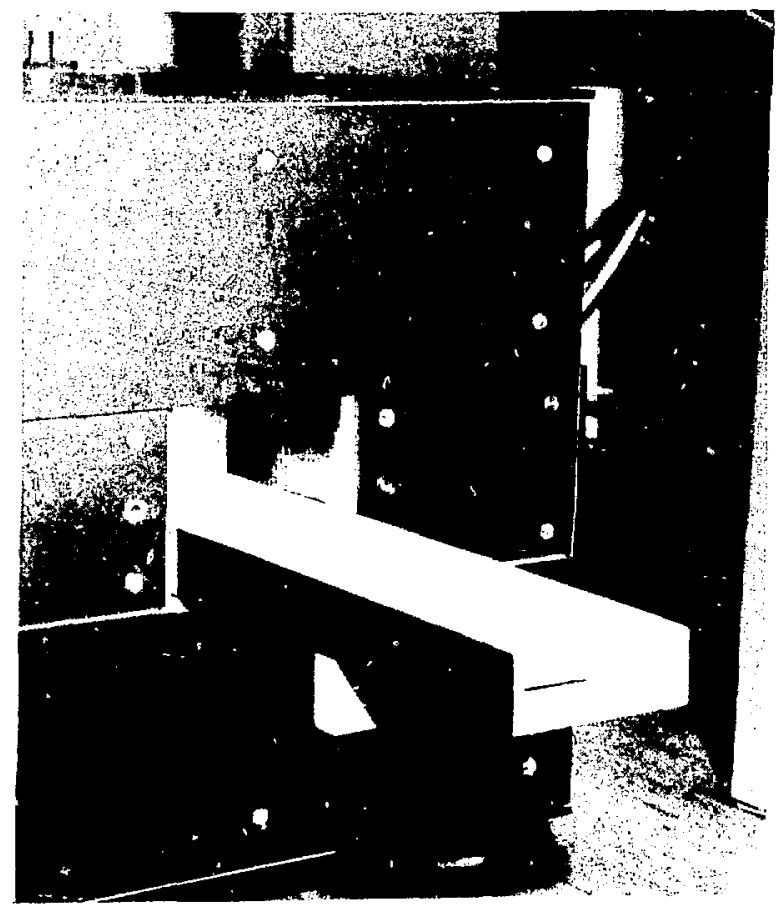

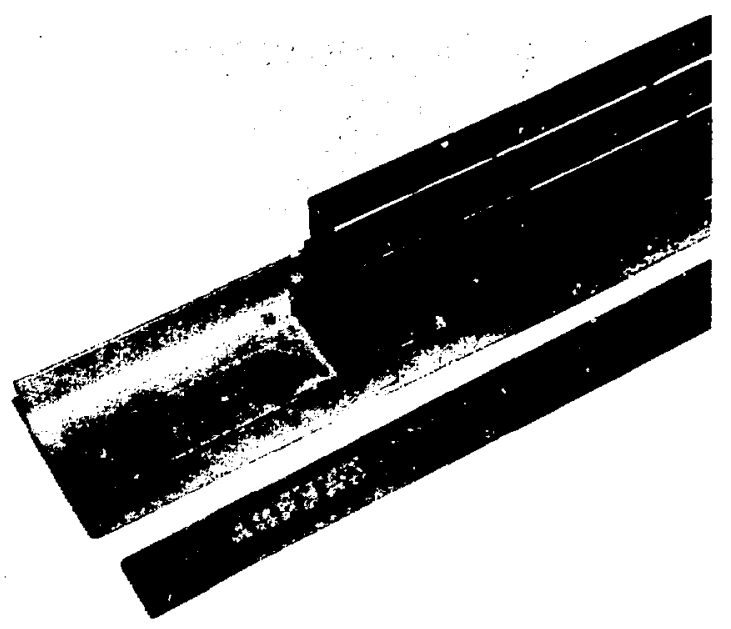

Fig. 17 .

Fuel tray with stop-bar and mockup FCA fuel drawer.
Fig. 18 .

Fuel tray fully inserted in detector channel with mockup FCA fuel drawer. 
A calibration curve for FCA drawers is shown in Fig. 19. The data used for the construction of this curve were acquired with zero Power Plutonium Reactor (ZPPR) fuel plates arranged in single, double, and triple rows with matrix materials of $\mathrm{Fe}, \mathrm{Al}, \mathrm{C}$, and depleted $U$. Due to uncertainties in isotopic composition of the ZPPR plates, more consistent results were obtained using plutonium nonfissile mass rather than the ${ }^{240}$ Pu-effective mass.

C. Assay of Plutonium-Bearing Fuel Pins

The two large brackets are removed from the bottom of the fuel tray and the small bar is removed from the top of the tray. The two remaining small brackets serve as spacers to hold the fuel pins near the center of the detector channel. The end plug must be removed. Figure 20 shows four mixed-oxide fuel rods loaded onto the fuel tray; Fig. 21 shows the tray inserted into the detector channel.

\section{Fuel Tray Used With HLNCC}

The two large brackets on the fuel tray allow the tray to be used with the HLNCC, as shown in Figs. 22 and 23. The small bar in the tray is removed. The support brackets are clamped to the top and bottom of the HLNCC body with the bolts threaded through '.he support brackets. One or two lab jacks are used to provide extra support at the end(s) of the tray. The black band painted on the front end of the tray shows where the plutonium fuel region is to stop for one measurement of a two-position FCA fuel drawer measurement (Fig. 22); for the second measurement, the plutonium fuel region is to stop at the end of the tray (Fig. 23). 


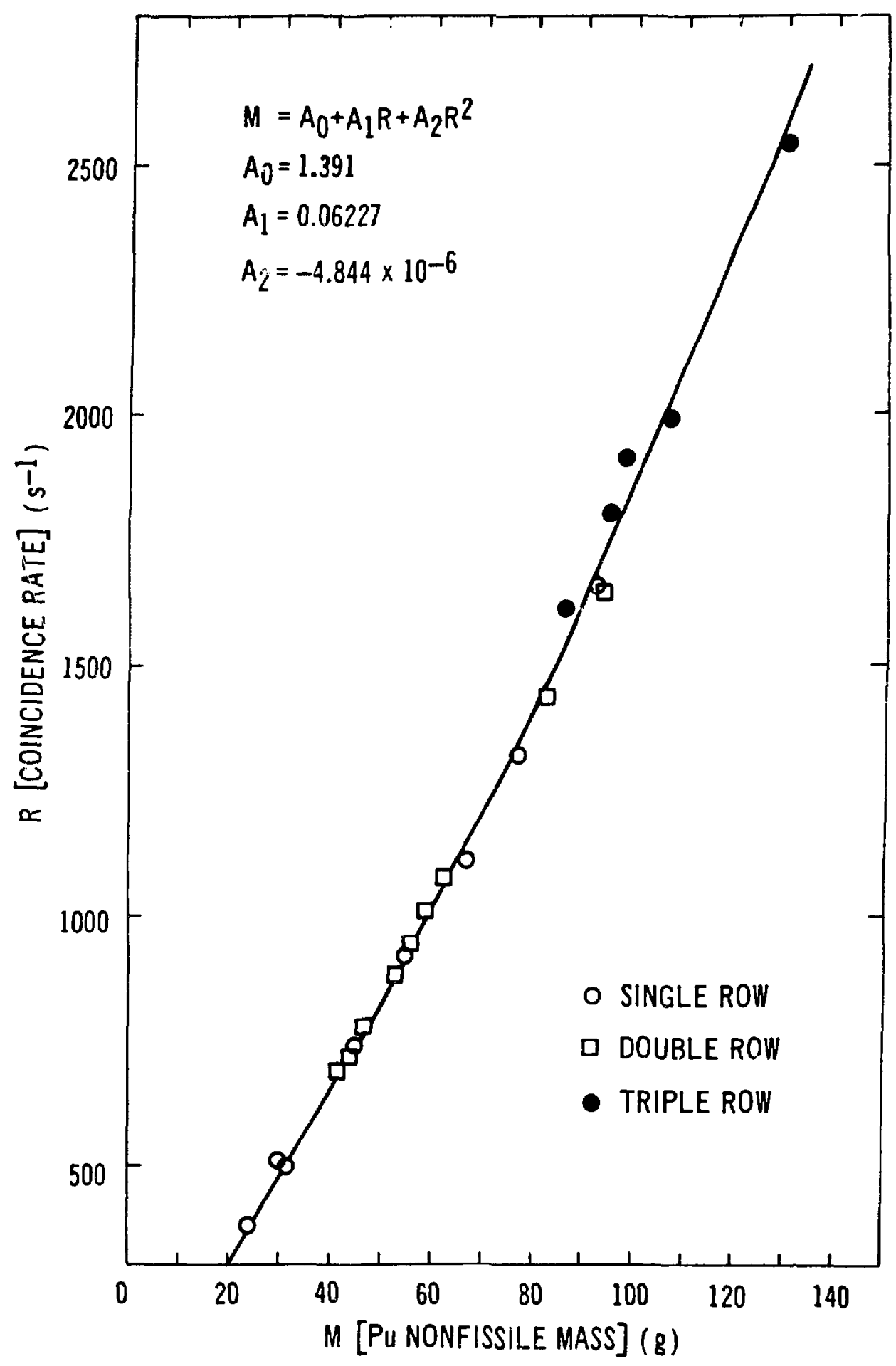

Fig. 19.

Calibration curve for FCA fuel drawers. 


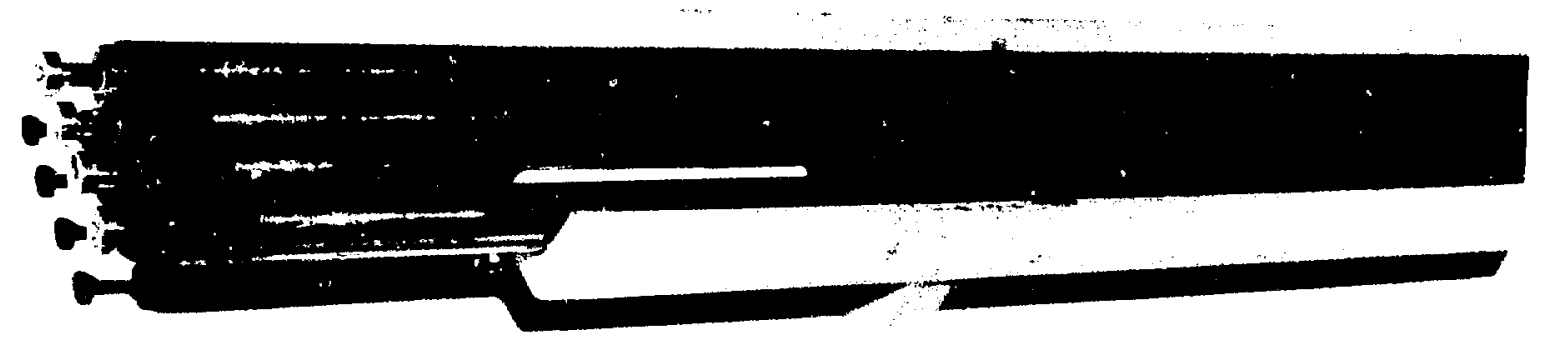

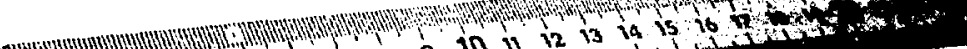

$1 \mathrm{~cm} 230$

7.m 2 n

Fig. 20.

Fuel tray with four mixed-oxide fuel rods.

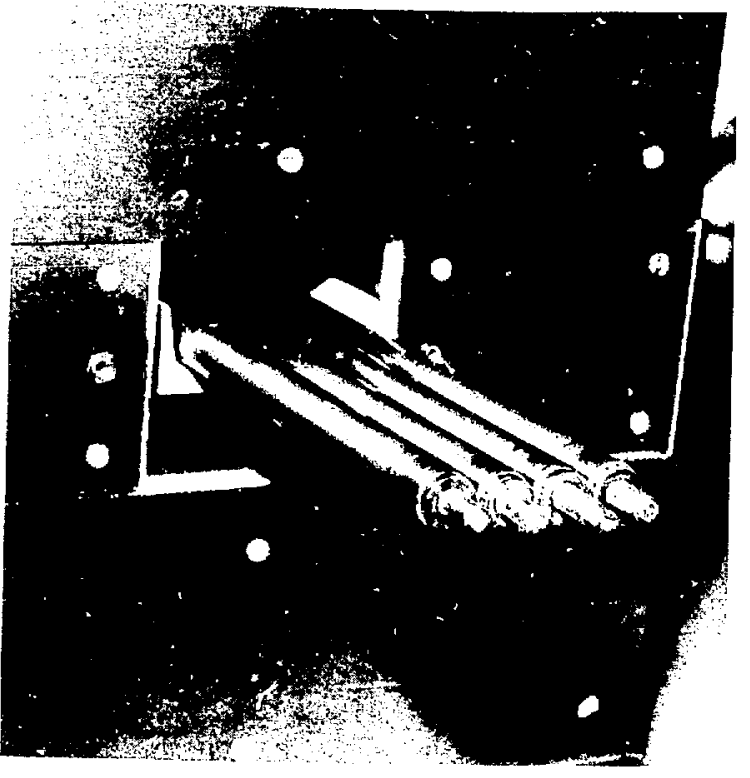

Fig. 21.

Fuel tray with four mixed-oxide fuel rods inserted into detector channel.

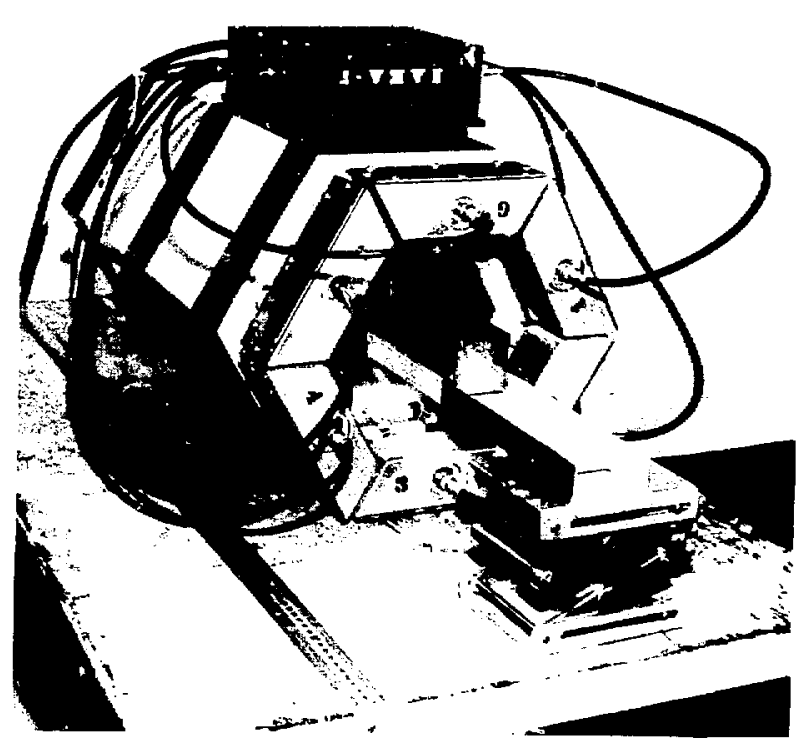

Fig. 22 .

Fuel tray with mockup FCA drawer in HLNCC (front view). 


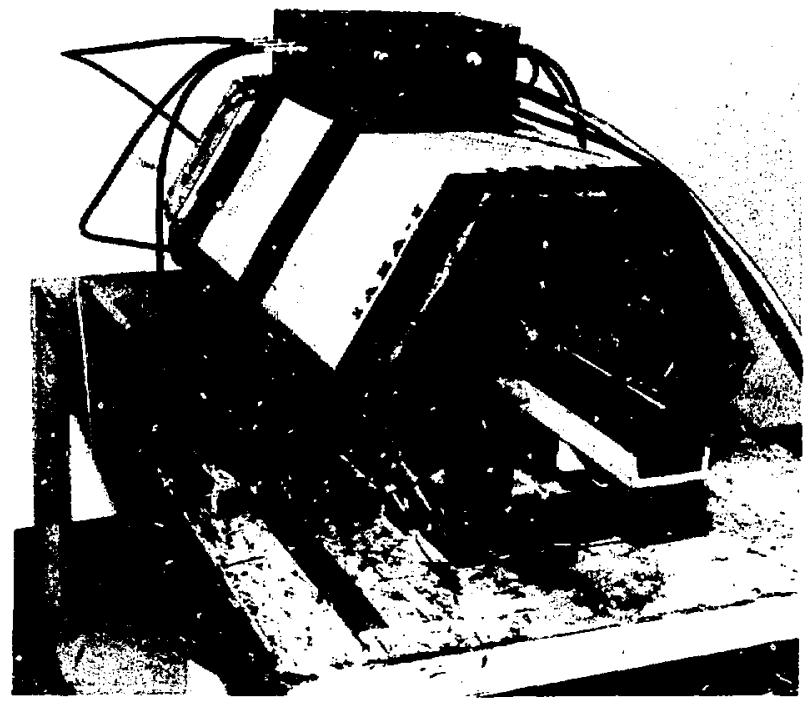

Fig. 23 .

Fuel tray with mockup FCA drawer in HLNCC (rear view).

REFERENCES

1. J. L. Sapir, H. O. Menlove, W. L. Talbert, M. de Carolis, and N. Beyer, "Calibration of the IAEA High-Level Neutron Coincidence Counter for Plutonium Plates in ZPPR Drawers," Los Alamos Scientific Laboratory report LA-6849-PR (1977) p. 4.

2. M. S. Krick and $H$. O. Menlove, "The High-level Neutron Coinci-dence Counter (HLNCC): Users' Manual," Los Alamor Scientific Laboratory report LA-7779-M (1979).

3. E. Medina ortega, Los Alamos Scientific Laboratory, private communication. 